\title{
Contribuiçõos para a elaboração de testes psicolinguísticos: construção de uma lista de sentenças
}

Maity Siqueira

Maitê Gil

Tamara Melo

\section{Resumo}

Neste artigo, são descritos dois estudos que visam à verificação de variáveis psicolinguísticas de uma lista de 135 sentenças envolvendo material linguístico metafórico e não metafórico. A noção de metáfora aqui adotada parte da perspectiva da Linguística Cognitiva, mais especificamente da Teoria da Metáfora Conceitual (LAKOFF e JOHNSON, 1980). O Estudo I $(n=200)$ busca averiguar a existência de uma correlação entre a convencionalidade de mapeamentos conceituais metafóricos primários e a familiaridade das expressões linguísticas metafóricas derivadas desses mapeamentos. O Estudo II $(n=316)$ objetiva verificar o grau de familiaridade, alerta e valência das sentenças que compõem a lista, as quais tiveram tamanho e complexidade sintática previamente controlados. A partir da lista de sentenças aqui elaborada, pretende-se contribuir para a construção de testes psicolinguísticos com material metafórico e não metafórico envolvendo as variáveis apresentadas ao longo dos estudos. Dessa forma, os resultados dos cuidados metodológicos descritos ao longo do artigo podem ser aplicados não só no âmbito da linguística, mas também em estudos de interface entre a linguagem e outras funções cognitivas.

Palavras-chave: lista de sentenças; cuidados metodológicos; psicolinguística; metáfora. 
A elaboração de um teste psicolinguístico exige atenção especial a fatores fundamentais inerentes a esse processo. $\mathrm{O}$ controle de variáveis, por exemplo, é essencial para se obter um maior grau de confiabilidade nos resultados finais. O presente trabalho descreve os passos para a construção de uma lista de sentenças envolvendo material literal e metafórico. A partir dos estudos aqui descritos, pretende-se fornecer um material linguístico controlado que possa ser utilizado em pesquisas psicolinguísticas. A abordagem que fundamenta o trabalho é a Teoria da Metáfora Conceitual (LAKOFF e JOHNSON, 1980), que se insere na perspectiva da Linguística Cognitiva.

A relevância deste artigo está no fato de que a literatura recente da área vem ressaltando a importância dos cuidados metodológicos nas pesquisas psicolinguísticas (GIBBS, 2007; GONZALEZ-MARQUEZ ET AL, 2007;), frente à exaustiva busca pela confiabilidade nos resultados obtidos. Como nos mostra Gibbs (2007), pesquisadores de outras áreas argumentam que os estudos cognitivos sobre a linguagem não são baseados em experimentos científicos objetivos, o que geraria análises muito subjetivas. Outra crítica, relacionada à primeira, reside na importância dada às intuições dos linguistas cognitivos nas suas pesquisas sobre a linguagem. Gibbs ressalta que, apesar de as reflexões dos pesquisadores serem um recurso valioso para a construção de hipóteses, devemos ser cautelosos ao aceitar os julgamentos linguísticos individuais. Além disso, o autor defende que os pesquisadores devem descrever e explicar mais detalhadamente os seus métodos, a fim de mostrar que eles levam a resultados consistentes. Low (2003), ao falar das pesquisas sobre metáfora, afirma que os critérios metodológicos relacionados aos modelos metafóricos ainda não estão bem estabelecidos. Após analisar cinco estudos na área, o autor propõe sugestões para trabalhos futuros - todas relacionadas à transparência e ao detalhamento de cada etapa da pesquisa.

Nesse sentido, o presente artigo pretende contribuir para estudos experimentais que envolvam sentenças literais e metafóricas, não só no âmbito da linguística, mas também para aqueles interessados em construir interfaces entre características da linguagem e outras funções cognitivas superiores, tais como: memória, atenção e percepção.

De fato, para a Linguística Cognitiva, a linguagem desempenha um papel central nos estudos da cognição, uma vez que, através da linguagem, é possível identificar aspectos do funcionamento de outras funções cognitivas humanas. Uma das hipóteses basilares com as quais a Linguística Cognitiva opera é a de que a linguagem não é uma faculdade cognitiva autônoma. A ideia de que a linguagem reflete certas propriedades da mente humana tem fortes implicações na agenda e nos métodos de pesquisa da Linguística Cognitiva. O chamado Compromisso Cognitivo (Co- 
gnitive Commmitment) representa a visão da Linguística Cognitiva de que os princípios que regem o funcionamento da linguagem humana devem ser psicologicamente plausíveis e devem estar em consonância com os pressupostos e achados de outras áreas das ciências cognitivas, tais como a Psicologia, a Neurologia e a Inteligência Artificial. Sendo assim, um modo de testar a adequação de hipóteses dentro da perspectiva aqui considerada é levar em conta as evidências convergentes de outras áreas da cognição (LANGACKER, 1999).

O material aqui desenvolvido foi elaborado de forma que possa ser utilizado em pesquisas que envolvam linguagem e outras funções cognitivas. Para isso, foram controladas e verificadas variáveis que serão detalhadas ao longo da apresentação dos estudos. Antes disso, porém, faremos uma breve exposição da Teoria da Metáfora Conceitual.

Conforme Lakoff e Johnson (1980), os proponentes dessa teoria, a metáfora é uma questão de central interesse no estudo da cognição, estando presente não só na linguagem, mas também no pensamento e na ação. Sob essa perspectiva, a metáfora deixa de ser exclusivamente uma questão do âmbito da linguística, isto é, algo que se relaciona somente com palavras, frases e expressões verbais. Mais do que isso, os processos do pensamento humano são amplamente metafóricos. Dessa forma, só é possível produzir e entender um enunciado metafórico porque as metáforas estão no sistema conceitual de cada indivíduo, sistema este que é evidenciado através da linguagem.

Assim, as expressões linguísticas metafóricas são a materialização das metáforas conceituais. É importante notar que a metáfora conceitual (doravante $\mathrm{MC}$ ) se distingue da metáfora linguística, na medida em que a primeira se refere a um nível abstrato do sistema conceitual, e a segunda se refere a um nível concreto de expressão linguística (SIQUEIRA, 2004). Em outras palavras, a MC é o entendimento de um domínio conceitual em termos de outro, e as metáforas linguísticas são expressões que tornam manifestas no nível da linguagem as relações abstratas das MCs.

As metáforas conceituais são formadas através de mapeamentos que partem de um domínio conceitual (fonte), tipicamente mais bem estruturado, que serve como fonte de inferências, para outro domínio conceitual (alvo), tipicamente mais abstrato, ao qual as inferências se aplicam. Assim, as pessoas têm, por exemplo, um conhecimento coerentemente organizado sobre o domínio conceitual TAMANHO, no qual se baseiam para com-

1 Neste trabalho, seguindo uma formalização amplamente estabelecida na Linguística Cognitiva, domínios conceituais e metáforas conceituais são apresentados em caixa alta. preender o domínio conceitual IMPORTÂNCIA, e esse processo propicia a formação da MC IMPORTÂNCIA É TAMANHO. ${ }^{1}$ Os falantes atualizam linguisticamente essa metáfora conceitual ao se referirem a uma pessoa ou a um evento importante através de metáforas linguísticas, como: Gandhi foi um grande homem ou 
A ida do homem à lua foi um grande feito. Ainda sobre a formação das metáforas conceituais, é preciso ressaltar a unidirecionalidade dos mapeamentos, já que, contrariando a visão clássica de que as metáforas expressariam similaridade entre dois domínios, as inferências podem ser feitas apenas do domínio fonte para o alvo e não no sentido oposto. Se o mapeamento fosse bidirecional, as pessoas falariam de objetos grandes em termos de sua importância, em sentenças do tipo Essa régua é muito importante, então não vai caber no meu estojo, e isso simplesmente não acontece.

As metáforas conceituais podem ser classificadas como primárias ou complexas. São consideradas metáforas primárias aquelas que resultam de interações entre particularidades dos aparatos físico e cognitivo humanos com suas experiências subjetivas no mundo, independentemente de língua e cultura (GRADY, 1997). Segundo Lakoff (comunicação pessoal), as metáforas complexas são combinações de metáforas primárias, e tais combinações são determinadas por aspectos culturais. Neste artigo, trataremos apenas de metáforas primárias.

Em nossas experiências diárias, existem algumas situações que se repetem mais frequentemente e que têm significados mais salientes, em função do modo como essas experiências estão relacionadas a nossos objetivos. As metáforas primárias são baseadas e motivadas pelas experiências corporais mais salientes e recorrentes, assim como pelo modo como o corpo humano funciona e interage com o mundo físico (YU, 1998). Uma vez que essas experiências são comuns à espécie humana, elas têm um elevado potencial de universalidade. A correlação entre o aumento de peso e uma maior dificuldade, por exemplo, é tão frequente na experiência humana, que as pessoas conceituam "mais difícil" em termos de "mais pesado", mesmo quando a medida de peso não se aplica literalmente. Essa correlação experiencial motiva atualizações linguísticas metafóricas como O dia foi pesado hoje ou O interrogatório foi mais leve do que o esperado.

Tal conjunto de correspondências sistemáticas entre um domínio fonte (tipicamente mais concreto ou acessível aos sentidos) e um domínio alvo (tipicamente mais abstrato) evidencia algumas relações intrínsecas entre a estrutura e o funcionamento típico do corpo humano e o modo como as pessoas conceituam sua experiência no mundo. Em suma, conforme a Teoria da Metáfora Conceitual, a metáfora tem bases corpóreas e experienciais.

Tendo em vista os pressupostos aqui apresentados e a relevância que os estudos empíricos têm na perspectiva adotada, passamos à descrição dos estudos desenvolvidos para a elaboração da lista de sentenças.

\section{Estudo I}

Neste primeiro estudo, o objetivo era averiguar a existência de uma correlação entre a convencionalidade de mapeamentos 
conceituais metafóricos primários e a familiaridade das expressões linguísticas metafóricas derivadas desses mapeamentos.

A familiaridade é definida como uma propriedade de expressões metafóricas inteiras e, por hipótese, está relacionada à frequência de uma dada manifestação linguística em uma mesma comunidade. A convencionalidade, por sua vez, é uma propriedade da relação entre mapeamentos conceituais e as expressões linguísticas oriundas desses mapeamentos, e representa o quão estabelecidas estão essas metáforas conceituais em uma determinada comunidade. Considerando-se que uma mesma metáfora conceitual convencional pode gerar metáforas linguísticas familiares e não-familiares, pretendeu-se, neste estudo, verificar a relação entre essas duas propriedades exclusivamente em metáforas conceituais primárias (SIQUEIRA e ZIMMER, 2006).

\section{Método}

O método utilizado para este estudo foi baseado na aplicação de duas escalas Likert (LANG, 1980) de cinco pontos, elaboradas especialmente para esta pesquisa. Uma delas objetivava verificar o nível de convencionalidade das metáforas conceituais e de suas expressões linguísticas, e a outra pretendia avaliar o seu grau de familiaridade.

\section{Participantes}

A amostra foi composta por 200 estudantes da Universidade Federal do Rio Grande do Sul, com média de idade de 24,75 anos $(\mathrm{dp}=5,6), 118$ do sexo feminino e 72 do masculino, de diversos cursos das áreas exatas e humanas. Sua participação era voluntária e anônima.

\section{Instrumentos}

Foram elaborados dois questionários para a realização deste estudo: um para a verificação do grau de convencionalidade das expressões e outro para a avaliação da sua familiaridade. No primeiro, foram utilizadas oito metáforas conceituais primárias: A FELICIDADE É PARA CIMA; INTENSIDADE DE EMOÇÃO É CALOR; BOM É CLARO; DIFICULDADE É PESO; ACEITAR É ENGOLIR; INTIMIDADE EMOCIONAL É PROXIMIDADE; IMPORTÂNCIA É TAMANHO; SIMPATIA É SUAVIDADE. A partir de cada uma delas, criou-se uma frase contendo expressões que as atualizavam linguisticamente, perfazendo, então, um total de oito frases testadas em cada questionário. A partir da metáfora conceitual TRISTEZA É PARA BAIXO, por exemplo, foi selecionada e apresentada a atualização linguística Estou me sentindo pra baixo, seguida da sua correspondência semântica não-figurada "para expressar minha tristeza". As frases foram listadas verticalmente em uma tabela (parcialmente representadas pela tabela 
1). No sentido horizontal, havia uma escala de cinco pontos na qual os participantes eram orientados a assinalar a opção correspondente a sua avaliação de cada frase. No segundo questionário, foram apresentadas, também em forma de tabela, somente as oito expressões linguísticas derivadas dos mapeamentos conceituais utilizados e suas respectivas escalas de cinco pontos, nas quais as frases deveriam ser classificadas quanto ao seu grau de familiaridade (parcialmente representadas pela tabela 2). Nesse segundo instrumento, não foram explicitadas as correspondências semânticas das frases, pois o objetivo era verificar o grau de familiaridade das expressões linguísticas quando descontextualizadas.

Tabela 1 - Convencionalidade

\begin{tabular}{|l|c|c|c|c|c|}
\hline $\begin{array}{c}\text { QUESTÕES SOBRE } \\
\text { CONVENCIONALIDADE } \\
\text { DOS MAPEAMENTOS }\end{array}$ & $\begin{array}{c}\text { Nada } \\
\text { convencional }\end{array}$ & $\begin{array}{c}\text { Pouco } \\
\text { convencional }\end{array}$ & $\begin{array}{c}\text { Medianamente } \\
\text { convencional }\end{array}$ & $\begin{array}{c}\text { Muito } \\
\text { convencional }\end{array}$ & $\begin{array}{c}\text { Totalmente } \\
\text { convencional }\end{array}$ \\
\hline $\begin{array}{l}\text { 1. "Estou pra baixo", para } \\
\text { expressar minha tristeza. }\end{array}$ & 1 & 2 & 3 & 4 & 50 \\
\hline $\begin{array}{l}\text { 2. "Hoje é um grande dia", } \\
\text { para dizer que hoje é um } \\
\text { dia importante. }\end{array}$ & 1 & 2 & 3 & 4 & 5 \\
\hline
\end{tabular}

Tabela 2 - Familiaridade

\begin{tabular}{|l|c|c|c|c|c|}
\hline $\begin{array}{c}\text { QUESTÕES SOBRE } \\
\text { FAMILIARIDADE DAS } \\
\text { EXPRESSÕES }\end{array}$ & $\begin{array}{c}\text { Nada } \\
\text { familiar }\end{array}$ & $\begin{array}{c}\text { Pouco } \\
\text { familiar }\end{array}$ & $\begin{array}{c}\text { Medianamente } \\
\text { familiar }\end{array}$ & Muito familiar & Totalmente familiar \\
\hline 1. "Estou pra baixo" & 1 & 2 & 3 & 4 & 5 \\
\hline 2. "Hoje é um grande dia" & 1 & 2 & 3 & 4 & 5 \\
\hline
\end{tabular}

A coleta dos dados foi realizada em grupos na sala de aula dos próprios alunos, os quais assinaram um termo de consentimento livre e esclarecido, elaborado conforme diretrizes éticas que regulamentam a pesquisa com seres humanos. A amostra foi dividida aleatoriamente em dois grupos, de forma que metade dos alunos respondeu individualmente ou ao questionário de convencionalidade ou ao de familiaridade. A coleta de dados iniciou após os participantes serem informados sobre os objetivos da pesquisa.

Em seguida, as instruções foram lidas em voz alta, ainda que elas estivessem escritas no questionário que cada participante recebeu, de modo que eles poderiam lê-las diretamente da sua folha, caso quisessem. Nas instruções para o teste de convencionalidade, foi explicado que, em cada língua, algumas expressões são mais aceitas para veicular determinadas idéias, enquanto outras nem tanto. Os participantes foram, então, instruídos a avaliar essas expressões, marcando, por exemplo, o quanto a frase Essa aula foi pesada (atualização linguística da metáfora conceitual DIFICULDADE É PESO) é convencional para expressar que a aula foi difícil, através das opções da escala: "nada convencional" (1), "pouco convencional" (2), "medianamente convencional" (3), 
"muito convencional" (4), ou "totalmente convencional" (5). No teste de familiaridade, era solicitado aos participantes que assinalassem uma das opções da escala, respondendo em que nível as expressões apresentadas lhes eram conhecidas/familiares: "nada familiar" (1), "pouco familiar" (2), "medianamente familiar" (3), "muito familiar" (4), ou "totalmente familiar" (5). Cada participante respondeu individualmente, no seu próprio ritmo, às questões propostas.

\section{Tratamento dos Dados}

Os dados obtidos foram analisados através de cálculos de média simples. Os resultados encontrados revelaram que, quando um mapeamento conceitual é considerado convencional, as expressões linguísticas metafóricas derivadas desses mapeamentos também são consideradas familiares. Todas as expressões apresentadas foram consideradas convencionais e familiares (média de 3,8 e de 3,6 respectivamente), considerando as escalas Likert de cinco pontos (para uma melhor visualização desses dados, ver fig. 1). A partir dessa constatação, foi elaborado um segundo estudo, descrito a seguir.

Figura 1. Grau de familiaridade e convencionalidade em português (L1).

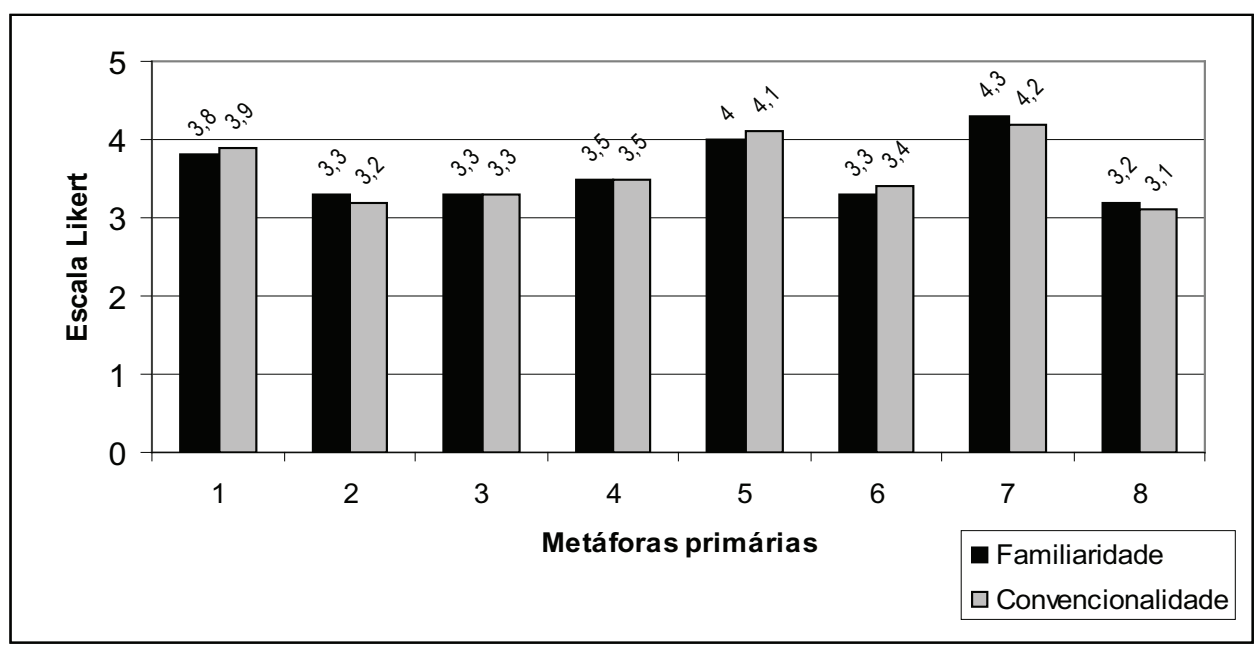

\section{Estudo II}

Neste estudo, buscamos verificar os níveis de familiaridade, alerta e valência, uma vez que estudos anteriores (REYNA e KIERNA, 1994; OCHSNER, 2000; KENSINGER e CORKIN, 2003) indicam que essas variáveis influenciam o funcionamento de outras capacidades cognitivas, tais como a memória. Alerta e valência são duas dimensões das experiências afetivas, ou seja, estão ligadas às emoções. A variável alerta se refere ao grau de excitação de uma pessoa em determinada situação, variando entre dois polos: calmo em um extremo e agitado em outro. Já a 
variável valência se refere ao grau em que uma resposta emocional a determinada situação é mais negativa ou positiva, variando, portanto, de altamente negativa a altamente positiva, passando pela valência neutra. As variáveis tamanho e complexidade sintática das sentenças foram controladas no processo de elaboração da lista de sentenças, conforme detalhado na seção Instrumento. A variável convencionalidade não foi controlada ou analisada, devido a sua correlação com a variável familiaridade, como indicaram os resultados obtidos no Estudo I.

\section{Método}

O método utilizado para este estudo foi baseado na aplicação de três escalas Likert de cinco pontos. A tabela de familiaridade (fig. 2) foi especialmente desenvolvida para este estudo, e as tabelas de alerta e valência foram adaptadas das escalas de Lang (1980).

Figura 2. Escala de familiaridade, alerta e valência

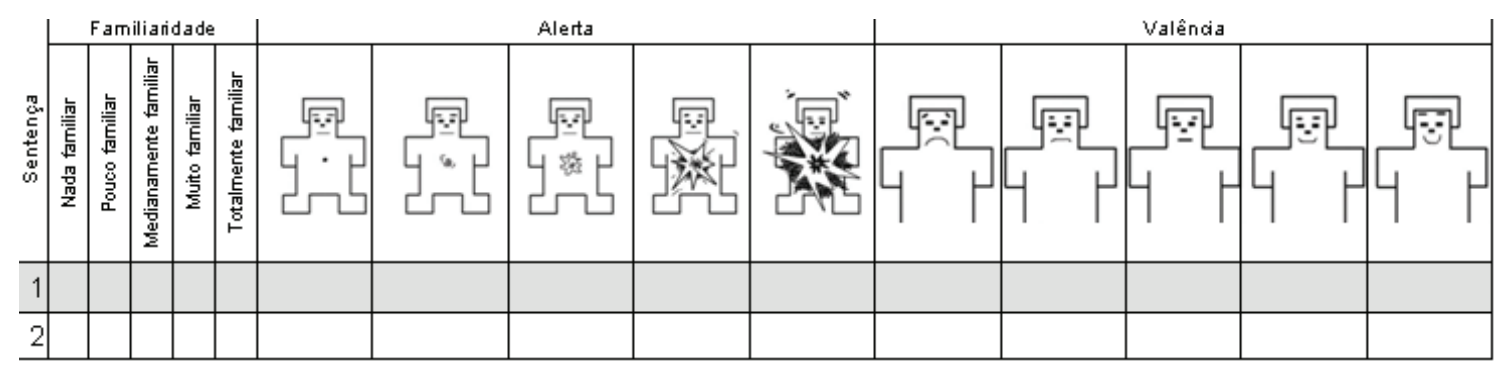

Participantes

A amostra foi composta por 316 estudantes, 155 do sexo feminino e 161 do masculino, da Universidade Federal do Rio Grande do Sul, de cursos distintos das áreas humanas e exatas. Sua participação era voluntária e anônima, e sua idade média era de 22,8 anos (dp = 5,7). Nenhum dos participantes do estudo II havia colaborado com o estudo I.

\section{Instrumentos}

Para a realização deste estudo, foram elaboradas 135 sentenças, sendo 67 literais e 68 metafóricas. Todas as sentenças eram atualizações linguísticas derivadas de metáforas conceituais primárias, ou suas respectivas paráfrases literais, todas de familiaridade presumidamente alta. Sempre que possível, foram formuladas duas sentenças metafóricas a partir do mesmo mapeamento (uma de valência presumidamente positiva e outra de valência presumidamente negativa) e duas paráfrases literais derivadas de cada uma das sentenças metafóricas (uma de valência presumidamente positiva e outra de valência presumidamente negativa). Em alguns casos, porém, não foi possível elaborar quatro frases a partir do mesmo mapeamento. Partindo do mapeamento RUIM 
É FEDOR, por exemplo, temos as atualizações linguísticas $A$ situação está fedendo e A situação está ruim, sentenças de valência presumidamente negativa e, respectivamente, metafórica e literal. A sentença metafórica de valência presumidamente positiva que atualizaria este mapeamento (A situação está cheirosa) não é usual em nossa comunidade, por isso não foi utilizada na pesquisa. Alguns mapeamentos, entretanto, possibilitavam somente atualizações linguísticas de valência presumidamente neutra. Nesses casos foi derivada somente uma sentença metafórica e sua paráfrase literal. Ao contrário da variável valência, os valores para a variável alerta não foram presumidos na construção das frases. Essa variável foi mensurada diretamente pelos participantes da pesquisa.

O tamanho das sentenças foi controlado e pareado em relação ao número de palavras e caracteres, dividindo a lista de sentenças em dois grupos: eram consideradas "pequenas" as frases de quatro até cinco palavras, com 15 a 25 caracteres, enquanto aquelas de cinco a sete palavras, com 26 a 35 caracteres, eram classificadas como "grandes". As sentenças originadas de um mesmo mapeamento preferencialmente enquadravam-se todas em um mesmo grupo, de sentenças grandes ou pequenas. Quando não era possível manter o sentido da sentença ou elaborar uma sentença familiar com o mesmo tamanho, optamos por manter o sentido e a frase mais familiar em detrimento do tamanho exato.

As sentenças foram também controladas quanto à complexidade sintática por dois juízes, professores universitários de linguística, a fim de parear suas estruturas e evitar que a complexidade gramatical influenciasse nos resultados de testes envolvendo outras funções cognitivas.

As 135 sentenças foram divididas em quatro blocos, de modo que três deles eram formados por 34 sentenças e o outro por 33. Essa divisão foi necessária para que um mesmo participante não respondesse a todas as 405 questões (135 sentenças $x 3$ variáveis), evitando assim que fatores como o cansaço prejudicassem as respostas finais. As atualizações linguísticas derivadas de uma mesma metáfora conceitual foram separadas nestes blocos, pois a proximidade das frases na lista de estudo poderia influenciar os resultados de testes psicolinguísticos posteriores, particularmente em casos de testes envolvendo memória. Ainda quanto à constituição dos blocos, observou-se o critério de distribuição equitativa no que diz respeito ao tipo de sentença (literal ou metafórica), ao tamanho das frases de cada um dos grupos e à valência presumida (positiva, negativa e neutra).

As sentenças foram, então, listadas em uma tabela, que continha as três escalas de cinco pontos distribuídas em linha. Essas escalas, intituladas familiaridade, alerta e valência, tinham o objetivo de avaliar as frases apresentadas (fig. 2). 


\section{Procedimentos}

A coleta dos dados foi realizada em grupos, na sala de aula dos próprios alunos, os quais assinaram um termo de consentimento livre e esclarecido, elaborado consoante as diretrizes éticas que regulamentam a pesquisa com seres humanos. Os participantes foram divididos aleatoriamente em quatro grupos, de maneira que a cada grupo foi apresentado um dos quatro blocos de sentenças do experimento. Após serem informados os objetivos da pesquisa aos participantes, foi iniciada a coleta propriamente dita.

Foi solicitado aos participantes, então, que avaliassem individualmente o quanto as frases a serem projetadas e lidas em voz alta lhes pareciam familiares ou não. Além disso, eles deveriam informar o quanto elas lhes pareciam estimulantes (alerta) e o quanto as sentenças eram agradáveis ou desagradáveis (valência). Ainda nas instruções, foram dados exemplos, como a sentença Fui numa festa, que pode ser considerada por alguns AGRADÁVEL e ESTIMULANTE, enquanto a frase Estou na praia pode também ser considerada AGRADÁVEL por um grande número de pessoas, porém RELAXANTE. Deste mesmo modo, foi apresentada uma frase considerada por muitos DESAGRADÁVEL e ESTIMULANTE, como Aconteceu um desastre, e também uma classificada como DESAGRADÁVEL e RELAXANTE por outros: Está chovendo. Foi ainda frisado que se tratava de uma avaliação subjetiva, não existindo respostas certas ou erradas, e que não havia uma relação direta entre as três classificações.

A seguir, as frases do bloco escolhido foram projetadas uma a uma, com um intervalo de 22 segundos entre elas, e pronunciadas em voz alta para que os participantes pudessem avaliá-las. A projeção foi feita com um datashow em um quadro branco.

\section{Tratamento dos Dados}

A partir dos dados obtidos, cada variável foi analisada individualmente. Para classificar as sentenças quanto a sua familiaridade, foram primeiramente calculados a média e o desvio padrão de todas as sentenças $(M=3,4 / d p=0,5)$. As frases que tinham média inferior a 2,9 (M-1dp) foram classificadas como não familiares. Em seguida, calculou-se a média e o desvio padrão geral da variável alerta $(M=2,9 / d p=0,6)$. Todas as sentenças que tinham sua média de alerta de 2,3 a 3,5 (M -1dp/ +1dp) foram consideradas frases de alerta médio, o que representa a grande maioria das 135 sentenças. As frases com médias inferiores a 2,3 foram consideradas de alerta baixo, enquanto aquelas com médias superiores a 3,5 foram consideradas de alerta alto. Para a valência, foi igualmente feito o cálculo de média e de desvio padrão $(\mathrm{M}=$ $3 / \mathrm{dp}=1$ ). A partir desses dados, foi elaborada a seguinte escala para a classificação das frases quanto a sua valência: sentenças 
com média até 2 (M -1dp) foram consideradas negativas; as com média de 2,5 a 3,5 foram classificadas como neutras ( $M-0,5 \mathrm{dp} /$ $+0,5 \mathrm{dp}$ ) e, por fim, aquelas com média acima de $4(\mathrm{M}+1 \mathrm{dp})$ foram definidas como positivas. Sugere-se que todas as sentenças que ficaram fora dessa margem, ou seja, as sentenças com média entre 2,1 e 2,4 e entre 3,6 e 3,9 sejam descartadas na elaboração de testes psicolinguísticos que envolvam o controle dessa variável.

Obteve-se, como produto do trabalho acima descrito, uma lista de 135 frases classificadas quanto ao tipo (literal ou metafórico) e ao tamanho (grande ou pequeno). Além disso, foram verificadas, em uma mesma comunidade linguística, as médias para familiaridade, alerta e valência dessas 135 frases, conforme a tabela 3, em anexo.

\title{
Considerações Finais
}

As pesquisas na área da psicolinguística necessitam de subsídios metodológicos confiáveis para obterem êxito. O controle de variáveis é um importante passo na exaustiva busca pela confiabilidade nos resultados obtidos através de testes psicolinguísticos. Os resultados dos estudos I e II são importantes para que seja possível a produção posterior de materiais adequados para a investigação de eventuais relações envolvendo sentenças literais e metafóricas e outras funções cognitivas, em testes que exijam um controle prévio das variáveis verificadas (tabelas 3 e 4, em anexo). Considerando, por exemplo, a capacidade mnemônica (REYNA e KIERNAN, 1994), as sentenças apresentadas neste artigo podem constituir um material confiável para verificar possíveis alterações no comportamento da memória quando submetida ao reconhecimento de sentenças literais e metafóricas.

A partir dos construtos teóricos e do estudo aqui apresentados, entendemos, portanto, que o controle de material linguístico envolvendo metáforas pode proporcionar um avanço para as pesquisas que correlacionem determinadas habilidades linguísticas a outras funções cognitivas.

\begin{abstract}
This article describes two studies aiming at the assessment of psycholinguistic variables from a list of 135 sentences containing methaporical and non-metaphorical linguistic material. The notion of metaphor adopted here stems from the framework of Cognitive Linguistics, more specifically from the Conceptual Metaphor Theory (LAKOFF and JOHNSON, 1980). Study I $(n=200)$ aims to inquire into the existence of a correlation between the conventionality of mappings involving primary conceptual metaphors and the
\end{abstract}


familiarity of linguistic metaphorical expressions derived from these mappings. Study II $(n=316)$ seeks to assess the degree of familiarity, arousal and valence of the sentences included in the list. These had their size and syntactic complexity previously controlled. Through the list of sentences elaborated here, this work aims to contribute to the development of psycholinguistic tests with metaphorical and non-metaphorical material involving the variables presented in the two studies. Thus, the results of the methodological precautions described in this article may be applied not only to studies in Linguistics, but also to studies dealing with the interface between language and other cognitive functions.

Keywords: list of sentences; methodological precautions; psycholinguistics; metaphor.

\section{REFERÊNCIAS}

GIBBS, Jr. R. W. Why cognitive linguists should care more about empirical methods. In: GONZALEZ-MARQUEZ, M. et al. Methods in Cognitive Linguistics. Amsterdam: John Benjamins, 2007.

GONZALEZ-MARQUEZ, M. et al. Methods in Cognitive Linguistics. Amsterdam: John Benjamins, 2007.

GRADY, J. Foundations of Meaning: primary metaphors and primary scenes. Tese de Doutorado. University of California, Berkeley, 1997.

KENSINGER E. A; CORKIN S. Memory enhancement for emotional words: Are emotional words more vividly remembered than neutral words? Memory and Cognition, 31(8), 1169-1180, 2003. LAKOFF, G.; JOHNSON, M. Metaphors we live by. Chicago: University of Chicago, 1980.

LANG, P. J. Behavioral treatment and bio-behavioral assessment: Computer applications. In: SIDOWSKI, J. B., JOHNSON, J. H.; WILLIAMS, T. A. (Eds.). Technology in mental health care delivery systems (p. 119-137). Norwood, NJ: Ablex, 1980.

LANGACKER, R. Assessing the cognitive linguistics enterprise. In: JANSSEN , T., REDEKER, G. (eds), Cognitive linguistics: Foundations, scope, and methodology. Berlin: Monton de Gruyter, p. 13-60, 1999.

LOW, G. Validating metaphoric models in applied linguistics. Metaphor and Symbol, n. 18, v. 4, p. 239-254, 2003.

OCHSNER, K. N. Are affective events richly recollected or simply familiar? The experience and process of recognizing feelings past. Journal of Experimental Psychology: General, 129, 242-261, 2000. 
REYNA, V;; KIERNAN, B. Development of Gist Versus Verbatim Memory in Sentence Recognition: Effects of Lexical Familiarity, Semantic Content, Encoding Instructions, and Retention Interval. Developmental Psychology, 30, n², 178-191, 1994.

SIQUEIRA, M. As metáforas primárias na aquisição da linguagem: um estudo interlinguístico. Tese de Doutorado não publicada. Pontifícia Universidade Católica do Rio Grande do Sul, Porto Alegre, RS, 2004.

SIQUEIRA, M. S. G.; ZIMMER, M. C. . Metáforas convencionais são metáforas familiares? In: III Conferência Linguística e Cognição, 2006, Campinas. Caderno de Resumos da III Conferência Linguística e Cognição, p. 31-32, 2006.

YU, N. The contemporary theory of metaphor. Philadelphia: John Benjamins, 1998. 



\section{Anexos}

Tabela 3 - Tipo, tamanho, familiaridade, alerta e valência ( $\mathrm{L}=$ literal, $\mathrm{M}=$ metafórica, $\mathrm{P}=$ pequena, $\mathrm{G}=$ grande)

\begin{tabular}{|c|c|c|c|c|c|c|}
\hline & Frase & Tipo & Tamanho & Familiaridade & Alerta & Valência \\
\hline 1 & Ele fica controlando o funcionário. & $\mathrm{L}$ & G & 3,5 & 2,3 & 2,0 \\
\hline 2 & Essa moda deixou de existir naquele ano. & $\mathrm{L}$ & G & 3,0 & 1,9 & 2,9 \\
\hline 3 & Meu trabalho está ficando melhor. & $\mathrm{L}$ & G & 3,8 & 3,6 & 4,3 \\
\hline 4 & O problema foi difícil de resolver. & $\mathrm{L}$ & G & 4,4 & 3,2 & 2,7 \\
\hline 5 & A situação mudou depois da aula. & $\mathrm{L}$ & G & 3,2 & 2,5 & 3,3 \\
\hline 6 & Ele é uma pessoa amável. & $\mathrm{L}$ & $\mathrm{P}$ & 3,7 & 2,9 & 4,1 \\
\hline 7 & Ele tem pouco conhecimento do tema. & $\mathrm{L}$ & G & 3,8 & 2,6 & 2,3 \\
\hline 8 & O time está perdendo no campeonato. & $\mathrm{L}$ & G & 4,2 & 2,8 & 2,0 \\
\hline 9 & Esse é um momento bom. & $\mathrm{L}$ & $\mathrm{P}$ & 4,0 & 3,7 & 4,4 \\
\hline 10 & Ele aceitou as desculpas. & $\mathrm{L}$ & $\mathrm{P}$ & 3,8 & 3,1 & 4,1 \\
\hline 11 & As teorias são diferentes. & $\mathrm{L}$ & $\mathrm{P}$ & 3,6 & 2,9 & 3,1 \\
\hline 12 & Esse foi um jogo honesto. & L & $P$ & 3,2 & 2,6 & 3,7 \\
\hline 13 & Essa aula foi difícil. & $\mathrm{L}$ & $P$ & 4,4 & 3,0 & 1,9 \\
\hline 14 & A proposta me interessa. & $\mathrm{L}$ & $\mathrm{P}$ & 3,8 & 3,8 & 4,0 \\
\hline 15 & O contrato ainda é válido. & $\mathrm{L}$ & $\mathrm{P}$ & 3,1 & 2,4 & 3,2 \\
\hline 16 & A situação está ruim. & $\mathrm{L}$ & $\mathrm{P}$ & 4,3 & 3,4 & 1,4 \\
\hline 17 & Nós já chegamos no nosso objetivo. & $\mathrm{M}$ & G & 3,4 & 3,4 & 4,2 \\
\hline 18 & Ele tem um jeito antipático. & $\mathrm{L}$ & $\mathrm{P}$ & 3,9 & 2,6 & 2,1 \\
\hline 19 & Nossa cidade fica morta à noite. & $\mathrm{M}$ & G & 3,4 & 2,1 & 2,2 \\
\hline 20 & Aquela idéia deu ótimos frutos. & $\mathrm{M}$ & G & 3,3 & 3,4 & 4,3 \\
\hline 21 & Estou me coçando para ver esse filme. & $\mathrm{M}$ & G & 3,1 & 3,2 & 3,6 \\
\hline 22 & O monumento está em péssima forma. & $\mathrm{M}$ & G & 2,4 & 2,1 & 2,2 \\
\hline 23 & Nossa amizade nasceu de repente. & M & G & 3,7 & 3,3 & 4,1 \\
\hline 24 & Ela atingiu o topo da carreira. & M & G & 3,1 & 3,0 & 3,8 \\
\hline 25 & O mercado financeiro esfriou um pouco. & $\mathrm{M}$ & G & 3,0 & 2,0 & 2,5 \\
\hline 26 & Aquela é uma pergunta central. & $\mathrm{M}$ & G & 2,7 & 2,5 & 3,0 \\
\hline 27 & Essa é uma arte maior. & $\mathrm{M}$ & $\mathrm{P}$ & 2,5 & 2,8 & 3,4 \\
\hline 28 & Ele está numa má posição no emprego. & $\mathrm{M}$ & G & 3,1 & 2,7 & 1,7 \\
\hline 29 & Estou me sentindo para baixo. & M & $\mathrm{P}$ & 4,2 & 2,7 & 1,3 \\
\hline 30 & Eu vou pesar a decisão. & M & $\mathrm{P}$ & 2,7 & 2,7 & 2,9 \\
\hline 31 & Meus colegas são distantes. & M & $\mathrm{P}$ & 3,1 & 2,2 & 1,8 \\
\hline 32 & Nosso namoro está quente. & M & $\mathrm{P}$ & 3,5 & 4,1 & 4,7 \\
\hline 33 & Ele machucou a minha honra & M & $\mathrm{P}$ & 2,2 & 3,2 & 1,7 \\
\hline 34 & Ele é uma pessoa amarga. & M & $\mathrm{P}$ & 3,8 & 2,7 & 1,8 \\
\hline 35 & O monumento está em péssimas condições. & $\mathrm{L}$ & G & 3,6 & 2,3 & 1,8 \\
\hline 36 & Essa moda passou a existir naquele ano. & $\mathrm{L}$ & G & 3,1 & 1,8 & 2,9 \\
\hline 37 & Aquela idéia deu ótimos resultados. & L & G & 4,1 & 3,6 & 4,5 \\
\hline 38 & Meu trabalho está ficando pior. & $\mathrm{L}$ & $\mathrm{G}$ & 3,6 & 3,5 & 1,2 \\
\hline 39 & Aquela é uma pergunta importante. & $\mathrm{L}$ & G & 4,1 & 3,5 & 3,4 \\
\hline 40 & Ele tem muito conhecimento do tema. & $\mathrm{L}$ & G & 4,1 & 3,2 & 3,8 \\
\hline
\end{tabular}




\begin{tabular}{|c|c|c|c|c|c|c|}
\hline 41 & Esse foi um jogo desonesto. & $\mathrm{L}$ & $\mathrm{P}$ & 4,0 & 3,5 & 1,7 \\
\hline 42 & A proposta não me interessa. & $\mathrm{L}$ & $\mathrm{P}$ & 3,6 & 2,3 & 2,4 \\
\hline 43 & Ela atingiu o máximo da carreira. & $\mathrm{L}$ & G & 3,3 & 3,3 & 4,0 \\
\hline 44 & Eu vou considerar a decisão. & $\mathrm{L}$ & $\mathrm{P}$ & 3,6 & 2,9 & 3,1 \\
\hline 45 & A situação virou depois da aula. & $\mathrm{M}$ & G & 2,9 & 3,0 & 2,9 \\
\hline 46 & Essa aula foi fácil. & $\mathrm{L}$ & $\mathrm{P}$ & 3,8 & 3,0 & 4,3 \\
\hline 47 & Ele prejudicou a minha honra & $\mathrm{L}$ & $\mathrm{P}$ & 2,4 & 3,5 & 1,4 \\
\hline 48 & Ele tem um jeito simpático. & $\mathrm{L}$ & $\mathrm{P}$ & 4,0 & 2,9 & 3,9 \\
\hline 49 & Nossa cidade ganha vida à noite. & $\mathrm{M}$ & $\mathrm{G}$ & 3,6 & 3,5 & 4,0 \\
\hline 50 & Ela é uma pessoa sofrida. & $\mathrm{L}$ & $\mathrm{P}$ & 4,0 & 2,9 & 1,6 \\
\hline 51 & O mercado financeiro esquentou um pouco. & $\mathrm{M}$ & $\mathrm{G}$ & 3,3 & 2,5 & 3,2 \\
\hline 52 & Ele fica em cima do funcionário. & $\mathrm{M}$ & $\mathrm{G}$ & 3,3 & 2,7 & 2,2 \\
\hline 53 & O problema foi duro de resolver. & $\mathrm{M}$ & $\mathrm{G}$ & 4,2 & 3,3 & 2,7 \\
\hline 54 & Ele está numa boa posição no emprego. & M & G & 3,8 & 3,2 & 4,1 \\
\hline 55 & Ele engoliu as desculpas. & $\mathrm{M}$ & $\mathrm{P}$ & 3,3 & 2,8 & 2,4 \\
\hline 56 & Nossa amizade morreu de repente. & $\mathrm{M}$ & $\mathrm{G}$ & 3,3 & 3,4 & 1,4 \\
\hline 57 & Ele é uma pessoa doce. & $\mathrm{M}$ & $\mathrm{P}$ & 3,8 & 2,8 & 4,1 \\
\hline 58 & Esse é um momento iluminado. & $\mathrm{M}$ & $\mathrm{P}$ & 3,2 & 3,5 & 4,3 \\
\hline 59 & O time está atrás no campeonato. & $\mathrm{M}$ & $\mathrm{G}$ & 3,8 & 2,8 & 2,1 \\
\hline 60 & As teorias são distantes. & $\mathrm{M}$ & $\mathrm{P}$ & 3,0 & 2,2 & 2,5 \\
\hline 61 & Estou me sentindo para cima. & $\mathrm{M}$ & $\mathrm{P}$ & 3,8 & 3,8 & 4,5 \\
\hline 62 & Essa é uma arte menor. & $\mathrm{M}$ & $\mathrm{P}$ & 2,7 & 2,1 & 2,4 \\
\hline 63 & Nosso namoro está frio. & $\mathrm{M}$ & $\mathrm{P}$ & 3,3 & 3,5 & 1,4 \\
\hline 64 & Nós já conseguimos o nosso objetivo. & $\mathrm{L}$ & G & 4,0 & 3,6 & 4,4 \\
\hline 65 & A situação está fedendo. & $\mathrm{M}$ & $\mathrm{P}$ & 3,6 & 3,4 & 1,7 \\
\hline 66 & O contrato está de pé. & $\mathrm{M}$ & $\mathrm{P}$ & 3,7 & 3,2 & 4,0 \\
\hline 67 & Ela precisa de ajuda no projeto. & $\mathrm{L}$ & G & 3,8 & 3,0 & 3,1 \\
\hline 68 & Estou querendo muito ver esse filme. & $\mathrm{L}$ & $\mathrm{G}$ & 4,8 & 4,0 & 4,3 \\
\hline 69 & Nossa cidade não tem atividade à noite. & $\mathrm{L}$ & $\mathrm{G}$ & 3,0 & 2,0 & 2,1 \\
\hline 70 & O momento da prova final chegou. & $\mathrm{M}$ & $\mathrm{G}$ & 4,1 & 4,1 & 2,5 \\
\hline 71 & O mercado financeiro ficou mais ativo. & $\mathrm{L}$ & G & 2,8 & 1,9 & 3,1 \\
\hline 72 & Ele está numa má situação no emprego. & $\mathrm{L}$ & $\mathrm{G}$ & 3,5 & 2,7 & 1,6 \\
\hline 73 & Ela precisa de apoio no projeto. & $\mathrm{M}$ & $\mathrm{G}$ & 3,0 & 2,6 & 3,0 \\
\hline 74 & Nossa amizade iniciou de repente. & $\mathrm{L}$ & $\mathrm{G}$ & 3,8 & 3,5 & 4,4 \\
\hline 75 & Esse é um momento ruim. & $\mathrm{L}$ & $\mathrm{P}$ & 3,9 & 3,6 & 1,4 \\
\hline 76 & Essa é uma arte irrelevante. & $\mathrm{L}$ & $\mathrm{P}$ & 2,5 & 2,3 & 2,4 \\
\hline 77 & Ela tem certeza desta idéia. & $\mathrm{L}$ & $\mathrm{P}$ & 3,7 & 2,9 & 3,2 \\
\hline 78 & Essa moda apareceu naquele ano. & $\mathrm{M}$ & $\mathrm{G}$ & 3,3 & 1,8 & 3,0 \\
\hline 79 & Há paralelos entre as duas histórias. & $\mathrm{M}$ & $\mathrm{G}$ & 3,1 & 2,6 & 3,3 \\
\hline 80 & Estou me sentindo feliz. & $\mathrm{L}$ & $\mathrm{P}$ & 4,3 & 4,2 & 4,8 \\
\hline 81 & Nosso namoro está sem emoção. & $\mathrm{L}$ & $\mathrm{P}$ & 2,7 & 2,8 & 1,5 \\
\hline 82 & Meus colegas são íntimos. & $\mathrm{L}$ & $\mathrm{P}$ & 2,8 & 2,5 & 3,5 \\
\hline 83 & Eu sei que existe solução. & $\mathrm{L}$ & $\mathrm{P}$ & 3,9 & 3,7 & 4,1 \\
\hline 84 & Ela está muito rancorosa. & $\mathrm{L}$ & $\mathrm{P}$ & 3,1 & 3,0 & 1,6 \\
\hline 85 & Ele é flexível em novas situações. & $\mathrm{M}$ & G & 3,1 & 2,4 & 3,6 \\
\hline 86 & Nós não chegamos no nosso objetivo. & M & G & 3,2 & 3,1 & 1,6 \\
\hline 87 & Esse foi um jogo sujo. & $\mathrm{M}$ & $\mathrm{P}$ & 3,5 & 3,7 & 1,5 \\
\hline
\end{tabular}




\begin{tabular}{|c|c|c|c|c|c|c|}
\hline 88 & O monumento está em ótima forma. & $\mathrm{M}$ & $\mathrm{G}$ & 2,0 & 2,0 & 3,3 \\
\hline 89 & As teorias são próximas. & $\mathrm{M}$ & $\mathrm{P}$ & 2,9 & 2,2 & 3,1 \\
\hline 90 & A proposta não me apetece. & $\mathrm{M}$ & $\mathrm{P}$ & 3,1 & 2,1 & 2,2 \\
\hline 91 & Ele tem conhecimento profundo do tema. & $\mathrm{M}$ & $\mathrm{G}$ & 3,9 & 3,1 & 3,8 \\
\hline 92 & Meu trabalho está indo para frente. & $\mathrm{M}$ & $\mathrm{G}$ & 3,4 & 3,6 & 4,3 \\
\hline 93 & Ele manchou minha imagem & $\mathrm{M}$ & $\mathrm{P}$ & 2,7 & 3,5 & 1,4 \\
\hline 94 & O problema foi fácil de resolver. & $\mathrm{L}$ & $\mathrm{G}$ & 3,9 & 3,1 & 4,3 \\
\hline 95 & O time está na frente no campeonato. & $\mathrm{M}$ & $\mathrm{G}$ & 4,0 & 3,1 & 3,9 \\
\hline 96 & Ele tem um jeito áspero. & $\mathrm{M}$ & $\mathrm{P}$ & 3,0 & 2,8 & 1,9 \\
\hline 97 & O contrato foi por terra. & $\mathrm{M}$ & $\mathrm{P}$ & 2,4 & 2,7 & 1,8 \\
\hline 98 & Eu entendi essa idéia rapidamente. & $\mathrm{L}$ & $\mathrm{G}$ & 4,0 & 3,4 & 4,3 \\
\hline 99 & Nós precisamos aperfeiçoar esse e-mail. & $\mathrm{L}$ & $\mathrm{G}$ & 2,9 & 2,0 & 2,6 \\
\hline 100 & Essa aula foi leve. & $\mathrm{M}$ & $\mathrm{P}$ & 3,5 & 2,6 & 4,3 \\
\hline 101 & Aquela é uma pergunta irrelevante. & $\mathrm{L}$ & $\mathrm{G}$ & 3,8 & 2,5 & 2,3 \\
\hline 102 & Ele tem desejo de poder. & $\mathrm{L}$ & $\mathrm{P}$ & 3,7 & 3,3 & 2,3 \\
\hline 103 & Nós não conseguimos o nosso objetivo. & $\mathrm{L}$ & $\mathrm{G}$ & 3,5 & 2,4 & 1,4 \\
\hline 104 & Essa moda desapareceu naquele ano. & M & G & 2,6 & 1,8 & 2,9 \\
\hline 105 & Ele está numa boa situação no emprego. & $\mathrm{L}$ & $\mathrm{G}$ & 3,7 & 3,2 & 4,1 \\
\hline 106 & O mercado financeiro ficou menos ativo. & $\mathrm{L}$ & G & 2,8 & 2,1 & 2,5 \\
\hline 107 & Nós precisamos limpar esse e-mail. & $\mathrm{M}$ & $\mathrm{G}$ & 3,7 & 2,3 & 2,3 \\
\hline 108 & O time está vencendo no campeonato. & $\mathrm{L}$ & $\mathrm{G}$ & 4,3 & 3,6 & 4,1 \\
\hline 109 & Nossa amizade acabou de repente. & $\mathrm{L}$ & $\mathrm{G}$ & 2,8 & 3,0 & 1,4 \\
\hline 110 & Estou me sentindo triste. & $\mathrm{L}$ & $\mathrm{P}$ & 3,8 & 2,7 & 1,2 \\
\hline 111 & Essa é uma arte importante. & $\mathrm{L}$ & $\mathrm{P}$ & 2,7 & 2,6 & 3,4 \\
\hline 112 & Aquela é uma pergunta periférica. & $\mathrm{M}$ & $\mathrm{G}$ & 1,8 & 1,6 & 2,8 \\
\hline 113 & Ele tem fome de poder. & M & $\mathrm{P}$ & 3,3 & 3,1 & 2,8 \\
\hline 114 & Nosso namoro está com emoção. & $\mathrm{L}$ & $\mathrm{P}$ & 2,9 & 3,6 & 4,0 \\
\hline 115 & Ele prejudicou minha imagem & $\mathrm{L}$ & $\mathrm{P}$ & 3,1 & 3,3 & 1,7 \\
\hline 116 & O problema foi mole de resolver. & $\mathrm{M}$ & $\mathrm{G}$ & 3,7 & 3,0 & 4,2 \\
\hline 117 & Eu peguei essa idéia rapidamente. & M & $\mathrm{G}$ & 3,7 & 3,4 & 4,1 \\
\hline 118 & O contrato não vale mais. & $\mathrm{L}$ & $\mathrm{P}$ & 2,9 & 2,7 & 2,4 \\
\hline 119 & Ela tem firmeza nesta idéia. & M & $\mathrm{P}$ & 3,2 & 2,9 & 3,3 \\
\hline 120 & Ele tem conhecimento superficial do tema. & M & $\mathrm{G}$ & 3,6 & 2,4 & 2,4 \\
\hline 121 & Meu trabalho está indo para trás. & M & $\mathrm{G}$ & 2,6 & 3,0 & 1,4 \\
\hline 122 & Esse foi um jogo limpo. & M & $\mathrm{P}$ & 3,4 & 2,7 & 3,9 \\
\hline 123 & Ele se adapta a novas situações. & $\mathrm{L}$ & G & 3,7 & 3,0 & 3,9 \\
\hline 124 & Esse é um momento sombrio. & M & $\mathrm{P}$ & 2,9 & 3,3 & 2,1 \\
\hline 125 & A proposta me apetece. & M & $\mathrm{P}$ & 3,0 & 3,1 & 3,9 \\
\hline 126 & Meus colegas são próximos. & $\mathrm{M}$ & $\mathrm{P}$ & 3,3 & 2,8 & 3,9 \\
\hline 127 & Essa aula foi pesada. & M & $\mathrm{P}$ & 4,4 & 2,9 & 3,5 \\
\hline 128 & Nossa cidade tem mais atividade à noite. & $\mathrm{L}$ & $\mathrm{G}$ & 3,5 & 3,2 & 3,6 \\
\hline 129 & Eu vejo que existe solução. & M & $\mathrm{P}$ & 3,8 & 3,7 & 4,3 \\
\hline 130 & Ela está cheia de rancor. & M & $\mathrm{P}$ & 3,3 & 2,7 & 1,6 \\
\hline 131 & O momento da prova final é agora. & $\mathrm{L}$ & G & 3,8 & 4,1 & 2,5 \\
\hline 132 & O monumento está em ótimas condições. & $\mathrm{L}$ & $\mathrm{G}$ & 2,7 & 2,2 & 3,7 \\
\hline 133 & Há semelhanças entre as duas histórias. & $\mathrm{L}$ & $\mathrm{G}$ & 3,4 & 2,5 & 3,2 \\
\hline 134 & Ele tem um jeito suave. & $\mathrm{M}$ & $\mathrm{P}$ & 2,5 & 1,9 & 3,3 \\
\hline 135 & As teorias são similares. & $\mathrm{L}$ & $\mathrm{P}$ & 3,3 & 2,3 & 3,1 \\
\hline
\end{tabular}


Tabela 4 - Metáforas Conceituais

\begin{tabular}{|c|c|}
\hline Frase & Metáfora Conceitual Correspondente \\
\hline 1,52 & CONTROLE É ACIMA \\
\hline $2,36,78,104$ & EXISTÊNCIA É VISIBILIDADE \\
\hline $3,38,92,121$ & MELHORA É PARA FRENTE \\
\hline $4,53,94,116$ & DIFICULDADE É DUREZA \\
\hline 5,45 & MUDANÇA É MOVIMENTO \\
\hline 6,57 & AMABILIDADE É DOÇURA \\
\hline $7,40,91,120$ & INTENSIDADE É PROFUNDIDADE \\
\hline $8,59,95,108$ & VANTAGEM É PARA FRENTE \\
\hline $9,58,75,124$ & BOM É CLARO \\
\hline 10,55 & ACEITAR É ENGOLIR \\
\hline $11,60,89,135$ & SIMILARIDADE É PROXIMIDADE \\
\hline $12,41,87,122$ & HONESTIDADE É LIMPEZA \\
\hline $13,46,100,127$ & DIFICULDADE É PESO \\
\hline $14,42,90,125$ & INTERESSANTE É SABOROSO \\
\hline $15,66,97,118$ & VÁLIDO É ERETO \\
\hline 16,65 & RUIM É FEDOR \\
\hline $17,64,86,103$ & ATINGIR UM PROPÓSITO É CHEGAR NUM DESTINO \\
\hline $18,48,96,134$ & SIMPATIA É SUAVIDADE \\
\hline $19,49,69,128$ & ATIVIDADE É VIDA \\
\hline 20,37 & IDÉIAS SÃO PLANTAS \\
\hline 21,68 & DESEJO DE AGIR É COCEIRA \\
\hline $22,35,88,132$ & CONDIÇÃO É FORMA \\
\hline $23,56,74,109$ & RELAÇÕES SÃO ORGANISMOS VIVOS \\
\hline 24,43 & SUCESSO É PARA CIMA \\
\hline
\end{tabular}




\begin{tabular}{|c|c|}
\hline $25,51,71,106$ & INTENSIDADE DE ATIVIDADE É CALOR \\
\hline $26,39,101,112$ & IMPORTÂNCIA É CENTRALIDADE \\
\hline $27,62,76,111$ & IMPORTÂNCIA É TAMANHO \\
\hline $28,54,72,105$ & SITUAÇÃO É POSIÇÃO \\
\hline $29,61,80,110$ & FELICIDADE É PARA CIMA \\
\hline 30,44 & CONSIDERAR É PESAR \\
\hline $31,82,126$ & INTIMIDADE É PROXIMIDADE \\
\hline $32,63,81,114$ & INTENSIDADE EMOCIONAL É CALOR \\
\hline 33,47 & PREJUDICAR É FERIR \\
\hline 34,50 & SOFRIMENTO É AMARGURA \\
\hline 67,73 & ASSISTÊNCIA É SUPORTE \\
\hline 70,131 & AGORA É AQUI \\
\hline 77,119 & CERTEZA É FIRMEZA \\
\hline 79,133 & SIMILARIDADE É ALINHAMENTO \\
\hline 83,129 & SABER É VER \\
\hline 84,130 & $\begin{array}{l}\text { SENTIMENTO É UMA SUBSTÂNCIA EM UM } \\
\text { RECIPENTE }\end{array}$ \\
\hline 85,123 & ADAPTABILIDADE É FLEXIBILIDADE \\
\hline 93,115 & PREJUDICAR É SUJAR \\
\hline 98,117 & ENTENDER É PEGAR \\
\hline 99,107 & IMPERFEIÇÃO É SUJEIRA \\
\hline
\end{tabular}

